\title{
Analysis of Iodine Deficiency Disorders in Kashi and Kizilsu Kirgiz Prefecture at Southern Edge of Tarim Basin in China
}

\author{
Ji-yong $\mathrm{J}^{1^{*}}$, Jiang Ning $\mathrm{BA}^{2}$, Wen Juan $\mathrm{MS}^{1}$, Wang Chen BA ${ }^{1}$, Ma Pin-jiang BA ${ }^{1}$ and TuJie MS ${ }^{1}$ \\ ${ }^{1}$ The Center for Disease Control and Prevention of Xinjiang Uygur Autonomous Region, Urumqi, Xinjiang, China \\ ${ }^{2}$ The Occupational Disease Hospital, Urumqi, Xinjiang, China
}

"Corresponding author: Jiang Ji-yong, The Center for Disease Control and Prevention of Xinjiang Uygur Autonomous Region, Urumqi, XinJiang CDC of Urumqi JianQuan street NO,380,China, Tel: 0086-991-2623301; Fax: 0086-991-2633500; E-mail: jjy1956@163.com

Rec date: Mar 07, 2014, Acc date: May 13, 2014, Pub date: May 15, 2014

Copyright: (C $2014 \mathrm{Ji}$-yong J, et al. This is an open-access article distributed under the terms of the Creative Commons Attribution License, which permits unrestricted use, distribution, and reproduction in any medium, provided the original author and source are credited.

\begin{abstract}
Objective: To investigate and analyze current situation of IDD (lodine Deficiency Disorders) control in Kashi and Kizilsu Kirgiz Prefecture at southern edge of Tarim Basin in China, in order to provide basis for implementing synthetic iodine supplement measures.

Methods: According to "Focus Investigation Program of IDD in Areas with High Risk in China" formulated by China Endemic Diseases Controlling Center, integrated survey and analysis were carried out in counties/cities of Kashi (12 counties/cities) and Kizilsu Kirgiz Prefecture (1 city and 3 counties). The urine samples of children and housewives from Kashi and Kizilsu Kirghiz regions were selected. The levels of iodine nutrition in the body were surveyed, and to study its effects in controlling endemic cretinism and regression of goiter. Totally there were 65 cases with endemic cretinism diagnosed in the two investigated prefectures. Investigation on table salt intake of residents was conducted by entering into households. In Kashi and Kizilsu Kirgiz Prefecture, coverage rate of iodized salt was $73.41 \%$ and $61.53 \%$, edible rate of qualified iodized salt was $64.62 \%$ and $54.23 \%$; edible rate of non-iodized salt (marsh salt and rock salt) was $26.59 \%$ and $38.47 \%$, respectively; Goiter rate of students aged from 8 to 10 year-old was $23.0 \%$ in Kashi and $13.6 \%$ in Kizilsu Kirgiz. There were 1921 cases detected with mild mental retardation $(\leq 69)$ in the two prefectures, accounted for $18.4 \%$. Median of urine iodine of the students was $136.5 \mu \mathrm{g} / \mathrm{L}$ in Kashi and $142.5 \mu \mathrm{g} / \mathrm{L}$ in Kizilsu Kirgiz. Urine iodine of women in child-bearing period was $85.5 \mu \mathrm{g} / \mathrm{L}$ in Kashi and $99.3 \mu \mathrm{g} / \mathrm{L}$ in Kizilsu Kirgiz.
\end{abstract}

Conclusions: Kashi and Kizilsu Kirgiz Prefecture in southern Xinjiang of China are severely endemic area of IDD. Intramuscular injection or oral intake of iodinated oil should be conducted in women in child-bearing period in the two prefectures, in order to avoid the birth with endemic cretinism. There is only qualitative standard for diagnosing endemic cretinism presently, and specifically quantitative experiment diagnosis is deficient. It needs for further research.

Keywords: Chinese racen's test; Endemic cretinism; Spectrophotometry; Myxedema

\section{Background}

In China, Xinjiang is a minority autonomous region where 47 nationalities live in compact communities and multiple religions coexist, including Uygur, Han, Kazak, Hui, Mongolia and so on. Xinjiang is located in the northwestern part of China and Eurasian Continental inland, far away from oceans, with unique physical geography of three huge mountain ranges running across and two enormous basins lying between the three mountains. Sea wind hardly approaches. So iodine resources are extremely short in the external environment. Xinjiang has been one of the severest areas of iodine deficiency at home and abroad. In 94 counties/cities/prefectures of Xinjiang, there is prevalence of IDD, and the severe endemic areas mainly concentrate on the areas around Tarim Basin and TurpanHami Basin. According to the previous documents, in 1960s before developing IDD control with iodine in large scale in Xinjiang, median of urine iodine of the residents was less than $25 \mu \mathrm{g} / \mathrm{L}$, and endemic goiter rate averaged $87.1 \%[1,2]$. Intelligence disability of children resulted from endemic cretinism and iodine deficiency was very common. IDD in Xinjiang not only severely affects people's constitution and intelligence of all nationalities, but also restricts improvement of population quality, economic development and social progress. In the light of "Focus Investigation Program of IDD in Areas with High Risk in Xinjiang" formulated by The Health Department of Xinjiang Uygur Autonomous Region, investigation on current situation of IDD control in Kashi and Kizilsu Kirgiz Prefecture without reaching the stage goal of IDD elimination in southern Xinjiang, was conducted two times from April to July 2007.

\section{Introduction}

The southern region of Xinjiang is one of wards most severely threatened by Iodine Deficiency Disorders (IDD) both in china and in the world. Kashgar and Kizilsu Kirghiz has rich gram rock salt or Shoal salt, and easy to exploit. It is difficult to carry out the measure of universal iodized salt in both areas, so IDD is very serious in these areas. This study aimed to investigate the status of IDD in both areas, and to determine an appropriate measure for elimination of IDD. 
Citation: Ji-yong J, Jiang Ning BA, Wen Juan MS, Wang Chen BA, Ma Pin-jiang BA, et al. (2014) Analysis of lodine Deficiency Disorders in Kashi and Kizilsu Kirgiz Prefecture at Southern Edge of Tarim Basin in China. J Nutr Disorders Ther 4: 137. doi: 10.4172/2161-0509.1000137

Page 2 of 4

\section{Investigation contents and methods}

The volunteers of investigation and clinical diagnosis who were excluded other thyroid diseases. Nearby the surveyed primary school, housewives were randomly selected according to the cluster sampling.

\section{Searching for new suspicious cases with endemic cretinism}

It was carried out mainly in children under 10 years old born after January 1, 1997. Diagnosis of verification of the suspicious cases was carried out by clinical diagnosis group of endemic cretinism from The Center for Disease Control and Prevention of Xinjiang Uygur Autonomous Region.

\section{Examining children aged 8 to 10 year-old}

Five villages in focal counties and 3 villages in the secondary focal counties were sampled randomly. And 200 children at age from 8 to 10 year-old were examined thyroid volume by palpation and $B$ ultrasound. Meanwhile intelligence of the children was measured and their urinary samples were collected to analyze urine iodine.

\section{Household survey}

At every village, 30 families were selected and in every township 2 villages were selected to carry out household survey for investigating sources and kinds of table salt. Families' edible salt was collected to analyze iodine content with semi quantitative method. Edible salt and urine samples were collected from the selected housewives to measure iodine content of salt and urinary iodine.

\section{Investigation objects}

On basis of "Focus Investigation Program of IDD in Areas with High Risk in Xinjiang", the program was developed in Kashi and Kizilsu Kirgiz Prefecture.

Urinary samples of women in child-bearing period, pregnancy and lactation were collected to detect for urine iodine.

\section{Investigation method}

Diagnosis of new patients with endemic cretinism: The collected report cases were diagnosed with diagnostic criteria of endemic cretinism and sub-clinical endemic cretinism (WS104-1999) [3].

Investigation on intelligence: Chinese Racen's Test (Revised Edition for Rural Use) was taken to test and intelligence quotient was calculated with its norm.

Thyroid examination in children: Two method of palpation and B ultrasound were taken [4].

Detection for iodine in salt: Iodine content in table salt was detected with direct titration of GB/T13025-1999 [5].

Detection for iodine in urine: As3+-Ce4+ catalyzing spectrophotometry was performed (WS/T 107-2006) [6].

\section{Statistical analysis}

The data was recorded with EPI INFO database. Pediatric goiter for measurement datausing $\mathrm{x}^{2}$ test, the urine iodine and salt iodine for measurement data, the frequency distribution of urinary iodine both children and women was analyzed by using $t$ inspection method.

\section{Results}

\section{Diagnosis of new suspicious cretinism and other diseases}

All volunteers who got parental consent or owner's consent voluntarily accepted this check.

There were totally 65 cases with endemic cretinism diagnosed in 13 counties/cities of Kashi and Kizilsu Kirgiz Prefecture, including 56 case of neurologic type, 8 cases of myxedema and 1 case of the mixed type (Table 1).

\begin{tabular}{|l|l|l|l|l|l|l|}
\hline Prefecture & \multirow{2}{*}{$\begin{array}{l}\text { Endemic } \\
\text { counties }\end{array}$} & \multirow{2}{*}{$\begin{array}{l}\text { Endemic } \\
\text { townships }\end{array}$} & \multicolumn{4}{|c|}{ Type (cases) } \\
\cline { 4 - 7 } & & & $\begin{array}{l}\text { Neurologi } \\
\text { c }\end{array}$ & Myxedematous & Mixed & Total \\
\hline Kashi & 10 & 35 & 52 & 8 & 1 & 61 \\
\hline $\begin{array}{l}\text { Kizilsu } \\
\text { Kirgiz }\end{array}$ & 3 & 3 & 4 & 0 & 0 & 4 \\
\hline Total & 13 & 65 & 56 & 8 & 1 & 65 \\
\hline
\end{tabular}

Table 1: Findings of cretinism

\begin{tabular}{|c|c|c|c|c|c|c|}
\hline \multirow[t]{2}{*}{ Prefecture } & \multicolumn{3}{|l|}{ Palpation } & \multicolumn{3}{|l|}{ B ultrasound } \\
\hline & $\begin{array}{l}\text { Investigated } \\
\text { No. }\end{array}$ & $\begin{array}{l}\text { No. of } \\
\text { goiter }\end{array}$ & $\begin{array}{l}\text { Goiter } \\
\text { rate (\%) }\end{array}$ & $\begin{array}{l}\text { Investigated } \\
\text { No. }\end{array}$ & $\begin{array}{l}\text { No. of } \\
\text { goiter }\end{array}$ & $\begin{array}{l}\text { Goiter } \\
\text { rate } \\
(\%)\end{array}$ \\
\hline Kashi & 7048 & 1623 & 23.0 & 7038 & 1196 & 16.9 \\
\hline $\begin{array}{l}\text { Kizilsu } \\
\text { Kirgiz }\end{array}$ & 2480 & 337 & 13.6 & 2480 & 585 & 23.6 \\
\hline Total & 9428 & 1960 & 20.8 & 9518 & 1781 & 18.7 \\
\hline
\end{tabular}

Table 2: Findings of goiter in children aged from 8 to 10 year-old

\section{Findings of salt iodine and thyroid examination}

Totally 4614 samples of edible salt of residents were collected by entering households in 16 counties/cities of Kashi and Kizilsu Kirgiz Prefecture, including 3459 samples in Kashi, with the coverage rate of iodized salt of $73.41 \%$, intake rate of qualified iodinated salt of residents of $64.62 \%$ and intake rate of non-iodinated salt of $26.59 \%$; 1155 samples in 3 counties and one city of Kizilsu Kirgiz Prefecture, with the coverage rate of iodized salt of $61.53 \%$, intake rate of qualified iodinated salt of residents of $54.23 \%$ and intake rate of non-iodinated salt of $38.47 \%$.

Palpation was taken to examine 9428 children aged from 8 to 10 year-old in Kashi and Kizilsu Kirgiz Prefecture, covering 1960 persons with goiter with goiter rate of $20.8 \%$; 9518 persons were examined with B ultrasound, with goiter rate of $18.7 \%$ (Table 2).

\section{Intelligence examination}

Totally 9402 persons were examined, with slight mental retardation of (s69) 1921 cases, accounting for $18.4 \%$ (Table 3). 
Citation: Ji-yong J, Jiang Ning BA, Wen Juan MS, Wang Chen BA, Ma Pin-jiang BA, et al. (2014) Analysis of lodine Deficiency Disorders in Kashi and Kizilsu Kirgiz Prefecture at Southern Edge of Tarim Basin in China. J Nutr Disorders Ther 4: 137. doi: 10.4172/2161-0509.1000137

Page 3 of 4

\section{Examination for urine iodine}

Out of the examined 6845 children in Kashi, the median of urine iodine of the children was $136.5 \mu \mathrm{g} / \mathrm{L}$ with $45.2 \%$ less than $100 \mu \mathrm{g} / \mathrm{L}$ and $25.3 \%$ under $50 \mu \mathrm{g} / \mathrm{L}$. In Kizilsu Kirgiz Prefecture, the median of urine iodine of 2388 children was $142.5 \mu \mathrm{g} / \mathrm{L}$ with $42.4 \%$ less than 100 $\mu \mathrm{g} / \mathrm{L}$ and $24.1 \%$ under $50 \mu \mathrm{g} / \mathrm{L}$ (Figure 1).

The median of urine iodine samples of housewives in Kashi and Kizilsu Kirgiz Prefecture was $87 \mu \mathrm{g} / \mathrm{L}, 55.2 \%$ of them were less than $100 \mu \mathrm{g} / \mathrm{L}$ and $26.0 \%$ were under $50 \mu \mathrm{g} / \mathrm{L}$ (Figure 1 ).

\begin{tabular}{|l|l|l|l|l|l|}
\hline Prefecture & $\begin{array}{l}\text { Examined } \\
\text { counties }\end{array}$ & $\begin{array}{l}\text { Examined } \\
\text { No. }\end{array}$ & $\begin{array}{l}\text { No. of slight } \\
\text { mental } \\
\text { retardation( } \\
\leq 69)\end{array}$ & $\begin{array}{l}\text { Proportion } \\
\text { of slight } \\
\text { mental } \\
\text { retardation( } \\
\%)\end{array}$ & $\begin{array}{l}\text { Average } \\
\text { level of } \\
\text { intelligence }\end{array}$ \\
\hline Kashi & 12 & 6974 & 1353 & 20.8 & 79.7 \\
\hline $\begin{array}{l}\text { Kizilsu } \\
\text { Kirgiz }\end{array}$ & 4 & 2428 & 568 & 23.4 & 80.0 \\
\hline Total & 16 & 9402 & 1921 & 18.4 & 80.9 \\
\hline
\end{tabular}

Table 3: Findings of Intelligence of School children

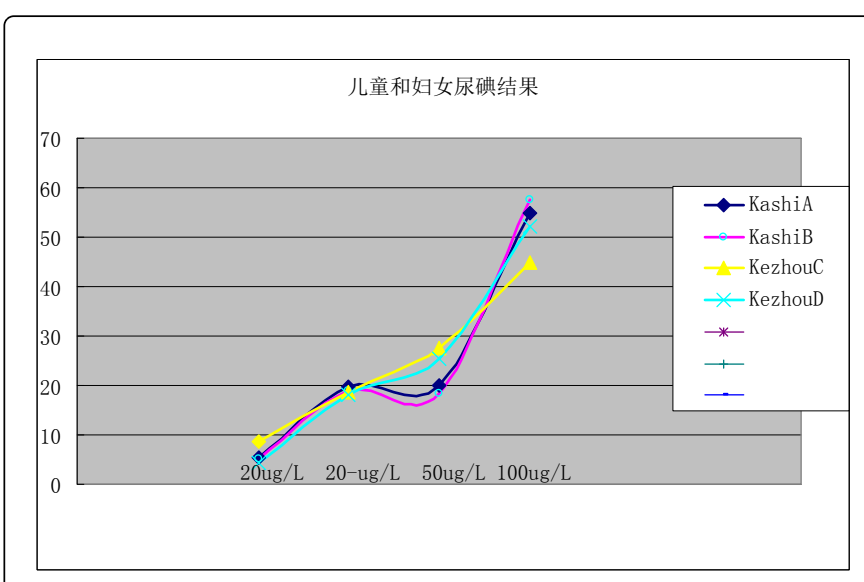

Figure 1: Urine iodine samples of housewives

\section{Discussion}

\section{Coverage rate of iodized salt and prevalence of endemic cretinism}

According to the diagnostic assessment endemic cretinism and subclinical cretinism, 65 patients less than 10 year-old with endemic cretinism (mainly neurologic and mixed type) were diagnosed by verification in 13 counties/cities in Kashi and Kizilsu Kirgiz Prefecture. Endemic cretinism, the congenital disease because of severe iodine deficiency in embryonic or neonatal period that results in thyroid hormone dyssynthesis, can attack the postnatal infant several months later [1]. The prevalent factors of endemic cretinism in southern Xinjiang of China are mainly due to the severe iodine deficiency in external environment, low edible rate of qualified iodized salt in residents. In both of the two prefectures, there were 50 families without intake of iodized salt and qualified iodized salt. Because of economic poverty for long-term and the habit of taking in marsh salt and rock salt [4], the women in child-bearing period didn't get iodine supplement before and after pregnancy. It is hard to implement synthetic measure of iodine supplement of iodized salt. The neonates continuously grow in the environment with severe iodine deficiency. Those are the major factors resulting in children's endemic disease in the two prefectures. There will be recurrence of cretinism if emergent measure of iodine supplement can't be taken as rapidly as possible to protect children from threatening of iodine deficiency to cerebral development.

\section{Goiter of children}

The goiter of children aged from 8 to 10 year-old was $20.8 \%$ in Kashi and Kizilsu Kirgiz Prefecture. There was big difference from the national standard for the stage goal of IDD elimination $\geq 5 \%$. Most correlation factors affects goiter of children, such as severe iodine deficiency in external environment in the investigated areas, resources of local salt (non-iodized salt) in the areas and no supplement of iodine in embryonic period. Under condition of sufficient supplement of iodized salt or other supplement of iodine preparation, even if thyroid function of children recovers to be normal, regression of goiter will take 5 years. The spread rate of iodized salt is low in the remote and impoverished areas of southern Xinjiang in China, with little intake of iodized salt (one time a day). Concentration of iodized salt must be regulated or improved, so as to effectively ameliorate iodine deficiency situation of local inhabitants, maintain physiologic equilibrium of iodine in human body and eliminate goiter.

\section{Qualified iodized salt and urine iodine of the inhabitants}

The findings indicated that edible rate of qualified iodized salt was $64.62 \%$ in Kashi and $54.23 \%$ in Kizilsu Kirgiz, while that of noniodized salt was 26.59 and $38.47 \%$, respectively. Sum of the percentage of non-iodized salt and non-qualified salt was basically more than the value of urine iodine of the children less than $100 \mu \mathrm{g} / \mathrm{L}$, that is, $45.2 \%$ in Kashi and $42.4 \%$ in Kizilsu Kirgiz. It illustrated that there were $50 \%$ investigated families without taking iodized salt and having intake of non-qualified iodized salt. The family members hadn't gotten iodine supplement or iodine deficiency in their body hadn't been improved. The research data confirmed that endemic goiter would occur but no endemic cretinism was prevalent when iodine intake amount of one person everyday was $40-80 \mu \mathrm{g} / \mathrm{L}$ [7]. The intake of iodine for each person daily less than $50 \mu \mathrm{g} / \mathrm{L}$ is the starting point of prevalence of endemic goiter. But there is also prevalence of endemic goiter in some areas where the urine iodine is out of normal range. Iodine deficiency affect over 2.2 billion individuals (38\% of the world's population, and is the leading cause of preventable mental retardation worldwide. Population iodine sufficiency is defined by median by urinary iodine concentration $\geq 100 \mu \mathrm{g} / \mathrm{L}$ in non-pregnant adults.

Pregnant women are the key population for IDD control. Their nutrition situation can directly influence fetal iodine nutrition and cerebral development. Specialists consider that the appropriate median of urine iodine of the pregnant be from 150 to $250 \mu \mathrm{g} / \mathrm{L}$. In this investigation, urine iodine of the women in pregnancy and childbearing period is lower than the normal level, due to influence of many factors on absorption and utilization of iodine in the body. According to the special geographical and geological environment in southern Xinjiang and living habit of the minorities [2], reasonable synthesis measures of iodine supplement must be taken and evaluated by combining with the thyroid function. In order to supple iodine reasonably, normal value of urine iodine of all people in the local area 
Citation: Ji-yong J, Jiang Ning BA, Wen Juan MS, Wang Chen BA, Ma Pin-jiang BA, et al. (2014) Analysis of lodine Deficiency Disorders in Kashi and Kizilsu Kirgiz Prefecture at Southern Edge of Tarim Basin in China. J Nutr Disorders Ther 4: 137. doi: 10.4172/2161-0509.1000137

Page 4 of 4

and cut-off of inducing goiter and cretinism must be calculated Factors of geography, food habits and heredity, etc. affect iodine metabolism in human body $[8,9]$ particularly concerning was the almost fourfold increase in the prevalence of urinary iodine values $<50$ $\mu \mathrm{g} / \mathrm{L}$ among women of child bearing age, from $4 \%$ to $15 \%$,over the two decades. Although women is $125 \mu \mathrm{g} / \mathrm{L}$ according to the most recent (2005-2008) NHANES data, 35.5\% have urinary iodine levels $<100$ $\mu \mathrm{g} / \mathrm{L}$. Thus, while the overall U.S. adult population remains iodine sufficient by WHO standards, a subset of pregnant and lactating women may have inadequate dietary iodine intake [10-13].

\section{Intelligence quotient (IQ) of the children}

Totally there were 20825 persons investigated. IQ of school children was lower 18.62 percentage points than that of the normal people, with 3831 cases of mild mental retardation $(\leq 69)$, accounting for $18.40 \%$. Iodine deficiency is one of the major reasons for inducing human mental retardation and psychomotor disorder. In southern Xinjiang, edible rate of iodized salt is low because of the impact of local salt (non-iodized rock salt and marsh salt). Iodine deficiency affects cerebral development of children with obvious impaired intelligence. Many factors can influence the intelligence of children. Mental retardation of various degrees, induced by brain injuries because of iodine deficiency in fetal period and age phase of 0 to 2 year-old, has been known [11]. It is difficult to spread iodized salt in remote and poor areas of southern Xinjiang in short term. Iodinated oil supplement in high-risk population is necessary and urgent in order to ensure iodine nutrition of the population and to prevent brain development of children from the injury of iodine deficiency.

\section{Conclusion}

In Kashi and Kizilsu Kirghiz regions, the status of Iodine Deficiency Disorders shows that endemic cretinism is caused by iodine deficiency in early Embryonic. Urinary iodine contents of 45.2 percent of children aged 8-10 years old and 55.2 percent of housewives were less than $100 \mu \mathrm{g} / \mathrm{L}$. The survey exhibits Kashi and Kizilsu Kirghiz is still severely threatened by Iodine Deficiency Disorders.

\section{References}

1. Gang L, Pinjiang M, Jiyong J (2011) Children's growth and development in Xinjiang iodine deficiency and iodine nutrition survey. Bull Dis Control Prev 26: 14-17.

2. Jiyong J, Bian H, Qing C (2004) Status of iodine deficiency disease control measures in Xinjiang and the main analysis. Endemic Disease Bulletin 19: 59-61.

3. Chinese Ministry of Health (1999) Endemic cretinism and endemic cretinism diagnosis of subclinical ws104-1999.

4. Chinese Ministry of Health (1995) Diagnosis and indexing standards endemic goiter.

5. China Light Industry (1999) General test method in salt industry measurement charged ions.

6. Chinese Ministry of Health (2006) Ammonium persulfate digestion of urinary iodine.

7. Xue-yi CAO (1987) Introduction to endemic diseases. (1stedn), The People's Medical Publishing House of Xinjiang, Urumqi.

8. Bian H, Ji-yong J, Gulina (2004) Dynamic observation on urine iodine level of children aged from 8 to 10 years old in Xinjiang from 1995 to 2004. Endemic Diseases Bulletin 19: 55-56.

9. Bian H, Xue-jun Y, Rui W (2001) The comparative analysis of uric iodine of the callans of the Han nationality from Shihezi, Kuitun and Tacheng in Xinjiang. Chinese Journal of Birth Health \& Heredity 9: 9.

10. Ji-yong J, Han-li C, Bing-chen X (2003) Investigation on current prevalence situation of IDD and influential factors affecting control measure implementation. Chinese Journal of Endemiology 22: 169-171.

11. Robert DG (2001) Effect of nutrition on cerebral development. Chinese Journal of Preventive Medicine 35: 63-66.

12. Hollowell JG, Staehling NW, Hannon WH, Flander DW, Gunter EW, et al. (1998) Iodine nutrition in the United States. Trends and public health implications: iodine excretion data from National Health and Nutrition Examination Surveys I and III (1971-1974 and 1988-1994). J ClinEndocrinolMetab 83: 3401-3408.

13. Caldwell KL, Makhmudov A, Ely E, Jones RL, Wang RY (2011) Iodine Status of the U.S. Population, National Health and Nutrition Examination Survey, 2005-2006 and 2007-2008. Thyroid 21: 419-427. 